\title{
Cahier iconographique
}

\section{(2) OpenEdition \\ 1 Journals}

Édition électronique

URL : http://journals.openedition.org/ccs/1497

DOI : $10.4000 /$ ccs. 1497

ISSN : 2558-782X

Éditeur :

Presses universitaires de Rennes, Association des lecteurs de Claude Simon

\section{Édition imprimée}

Date de publication : 30 août 2018

Pagination : I-IX

ISBN : 978-2-7535-7489-2

ISSN : 1774-9425

Référence électronique

"Cahier iconographique », Cahiers Claude Simon [En ligne], 13 | 2018, mis en ligne le 30 août 2019,

consulté le 20 février 2020. URL : http://journals.openedition.org/ccs/1497 ; DOI : 10.4000/ccs. 1497

Cahiers Claude Simon 


\section{RÉA SIMON}

\section{(1928-2017)}

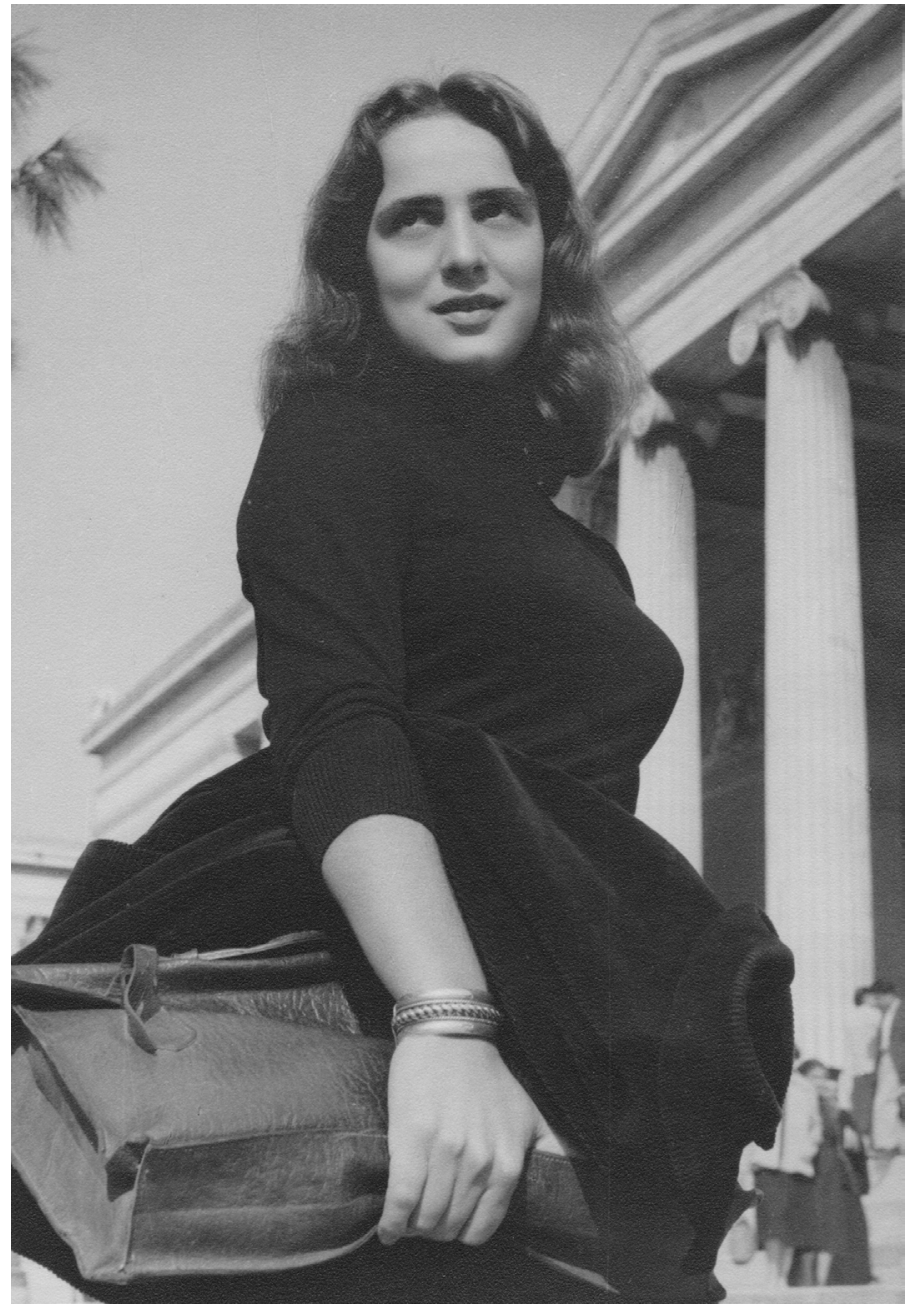

Réa Karavas, étudiante à Athènes dans les années 1950 


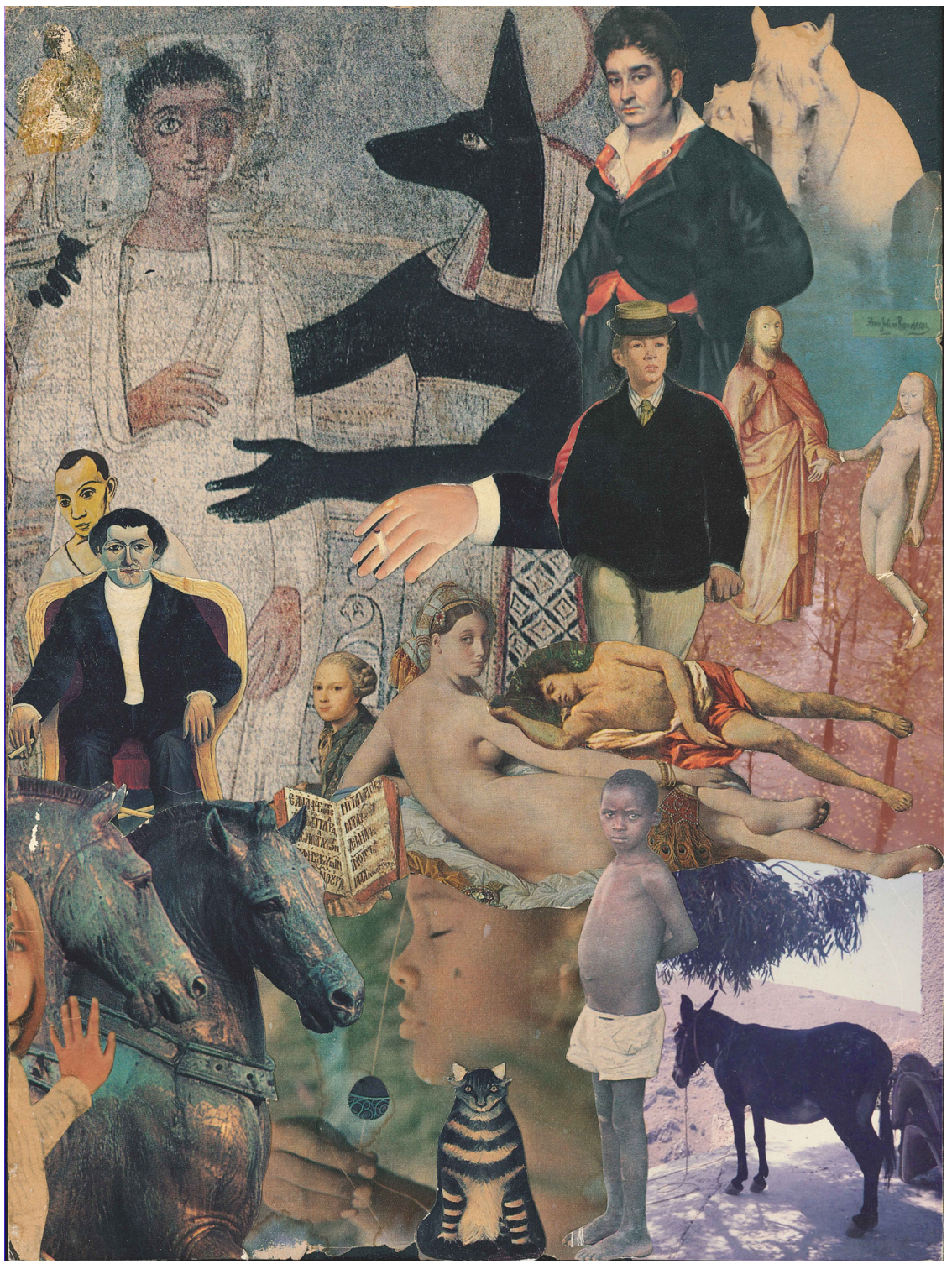

Réa Simon, Collage (non daté) 


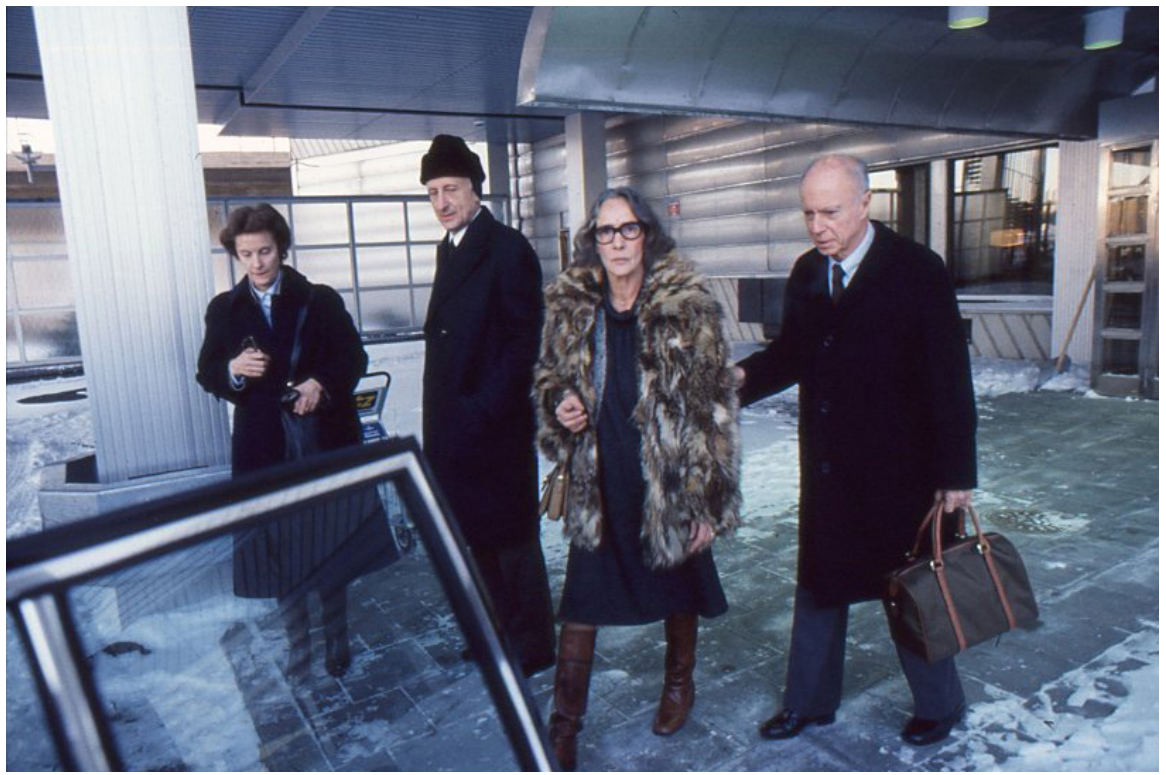

Jérôme Lindon, Réa et Claude Simon à Stockholm en décembre 1985 pour la réception du prix Nobel 


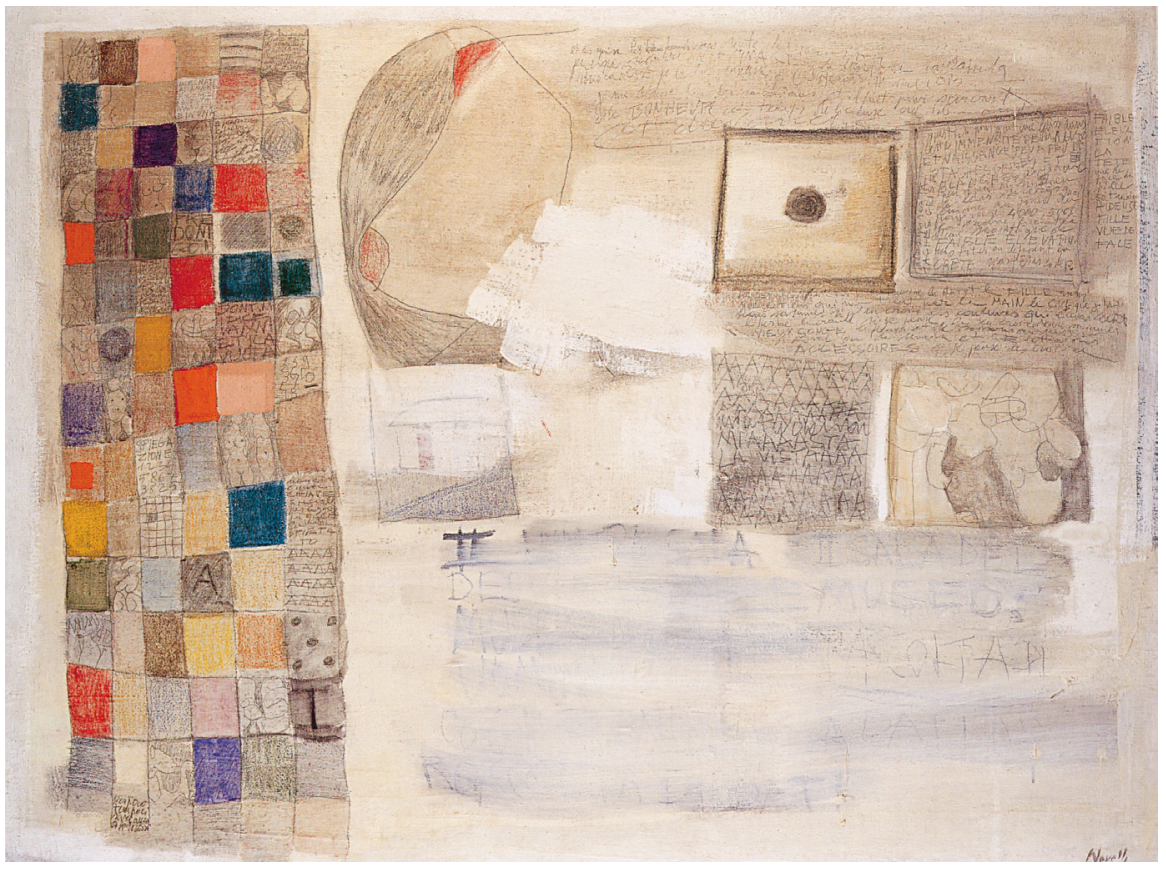

Gastone Novelli, Seconda sala del museo (1960) 


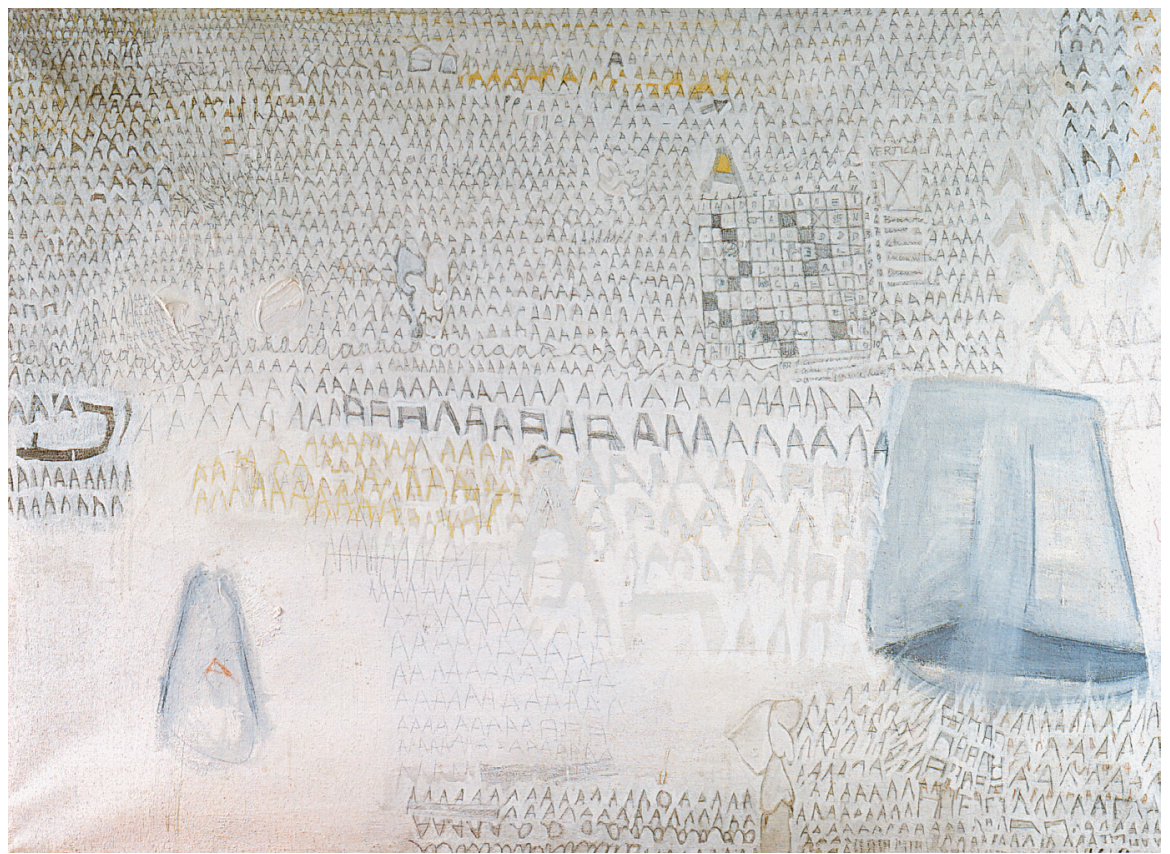

Gastone Novelli, A (1960) 


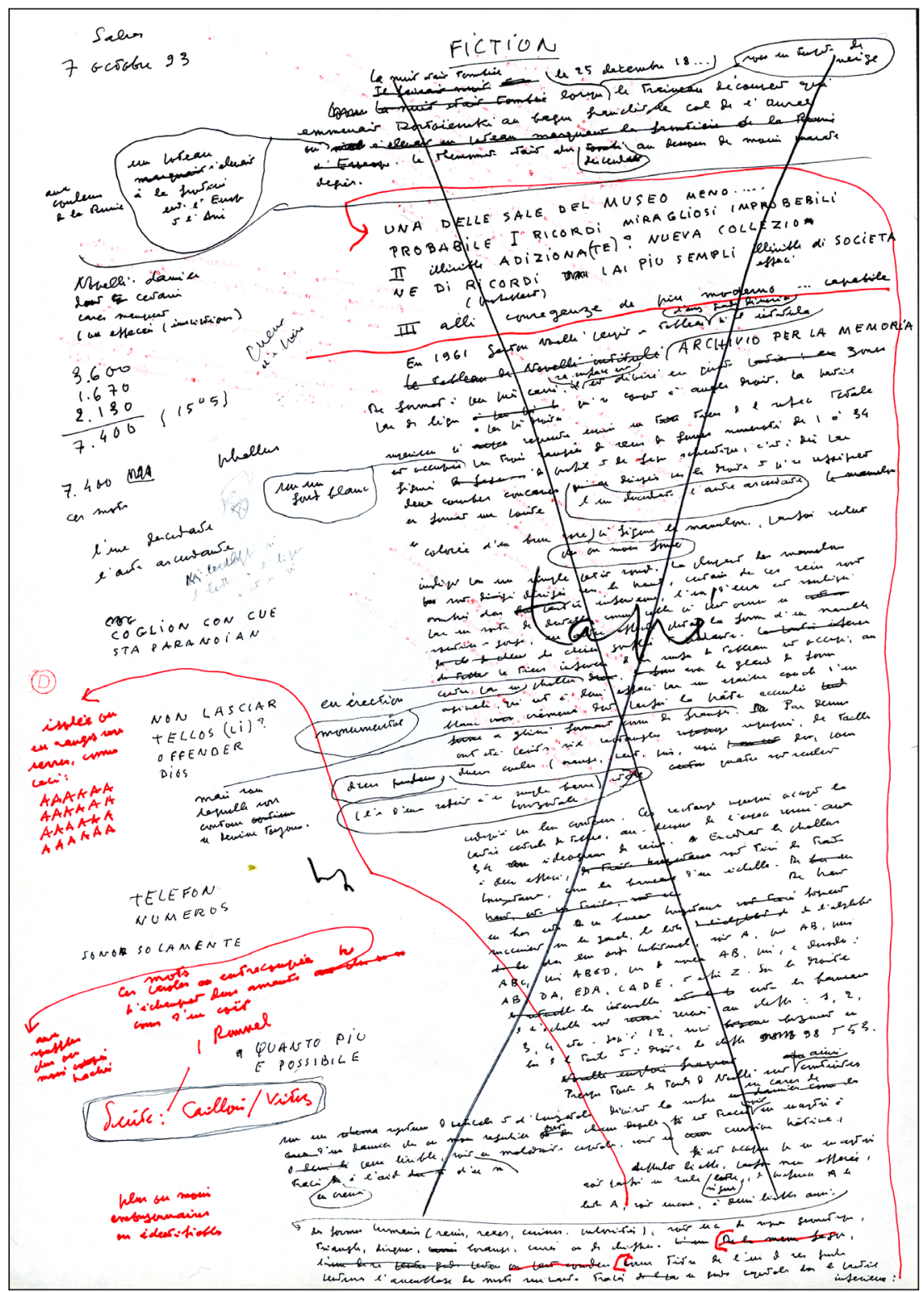

Manuscrit du Jardin des Plantes (7 oct. 1993, "Fiction ») 


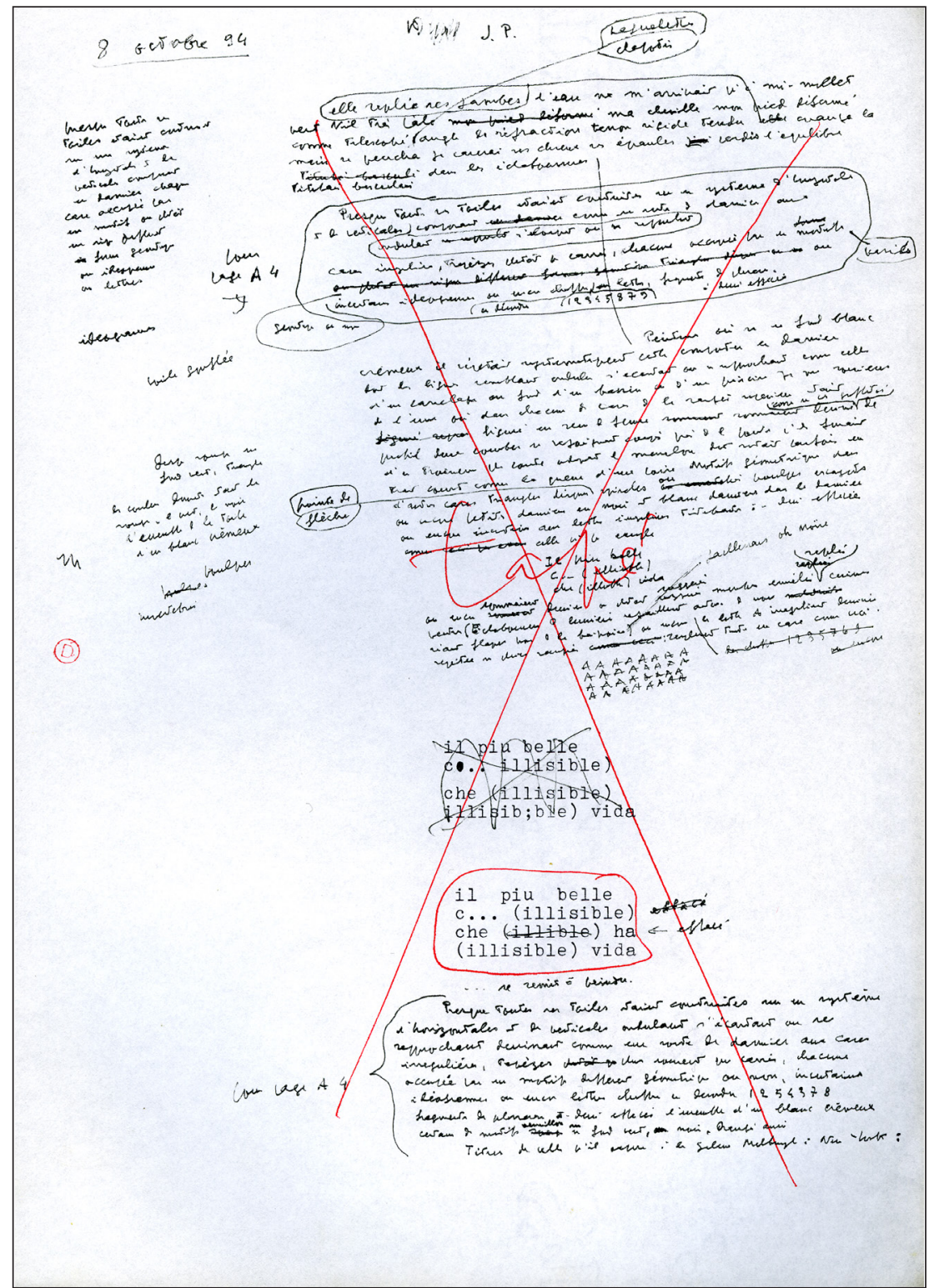

Manuscrit du Jardin des Plantes (8 oct. 1994, « J. P. ») 


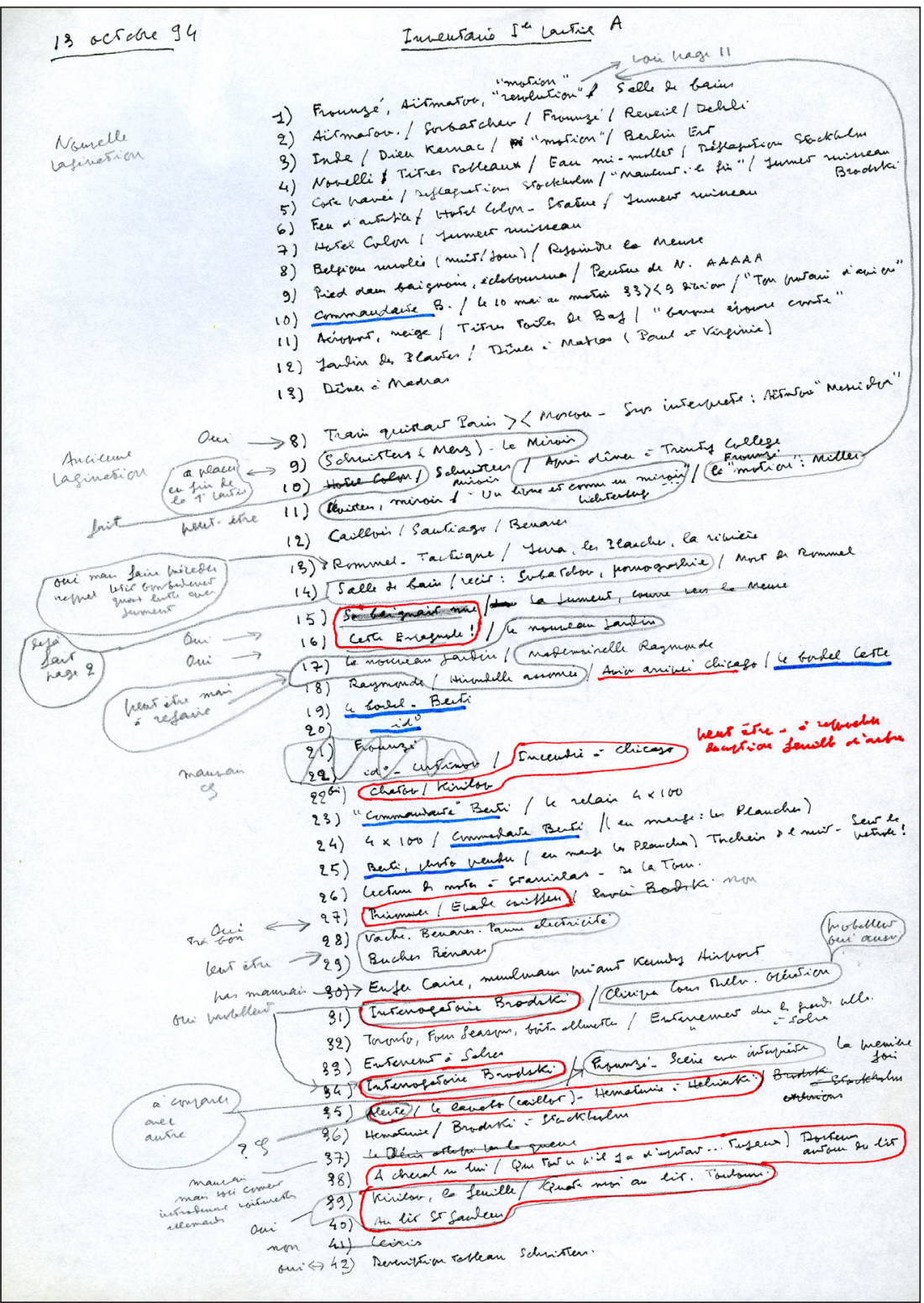

Manuscrit du Jardin des Plantes (13 oct. 1994, "Inventaire $\mathrm{I}^{\mathrm{re}}$ partie A ») 


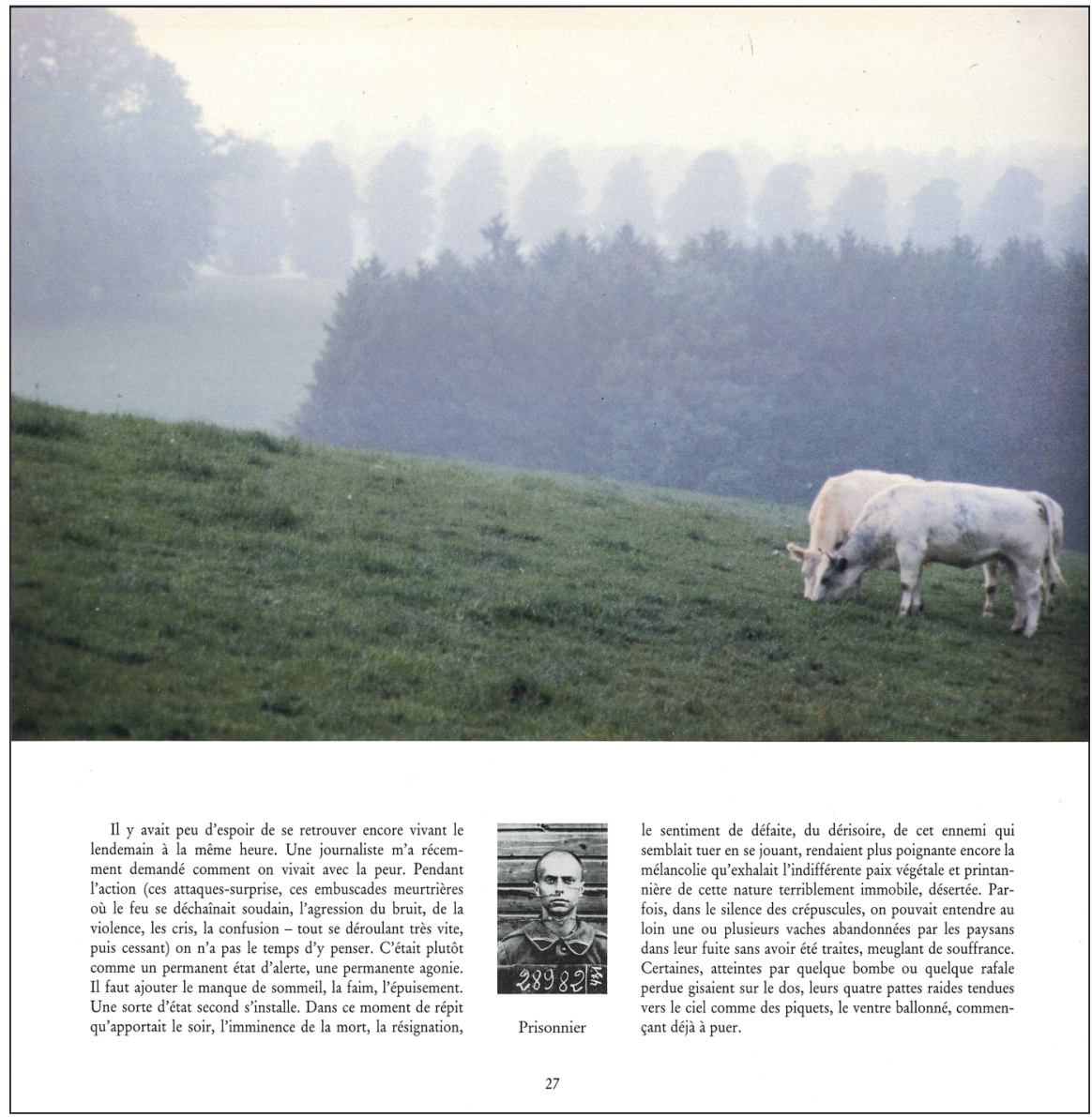

Album d'un amateur, p. 27 


\section{CRÉDITS PHOTOGRAPHIQUES}

Page I: droits réservés (remerciements à Patrick Longuet); page II : droits réservés, avec l'aimable autorisation d'Aristides Balanos; page III: (C) Roland Allard; pages IV-v: publié avec l'aimable autorisation d'Ivan Novelli; pages VI-VIII : manuscrits SMN 18(1), resp. 226, 416 et 334, (C) Claude Simon, avec l'aimable autorisation de la Bibliothèque littéraire Jacques Doucet et de Mireille Calle-Gruber, ayant droit moral pour l'œuvre de Claude Simon; page Ix: Album d'un amateur, Remagen-Rolandseck, Rommerskirchen, 1988,t, p. 27, () Claude Simon, avec l'aimable autorisation de Mireille Calle-Gruber. 